\title{
A HIGH STEP-UP DC/DC CONVERTER FOR MARINE APPLICATIONS
}

\author{
J. S. ASHWIN ${ }^{1} \&$ N. MANOHARAN ${ }^{2}$ \\ ${ }^{I}$ Research Scholar, Department of Electrical and Electronics Engineering (Marine), AMET University, \\ Chennai, Tamil Nadu, India \\ ${ }^{2}$ Rector, AMET University, Chennai, Tamil Nadu, India
}

ABSTRACT
In this paper, a voltage-doubler circuit with high step-up dc-dc converter has been proposed. This proposed
converter minimises low voltage stress on the MOSFET switches and high voltage gain with suitable duty ratio and, the
energy stored and it can be recycled to the output results. The proposed converter steady-state analysis are discussed in
detail and simulated in Matlab/Simulink software.
KEYWORDS: Voltage-Doubler, DC-DC Converter, Matlab/Simulink

Received: Oct 05, 2017; Accepted: Oct 25, 2017; Published: Jan 24, 2018; Paper Id.: IJMPERDFEB201888

\section{INTRODUCTION}

DC/DC converters are used boost the voltage from low voltage to high voltage. Highly utilised for motor control in electric vehicles, marine cranes (Zogogianni 2016). In The Evaluation of the Antibiofilm Properties of Arthrobacter defluvii AMET1677 Strain Isolated from Shrimp Pond Sediment against Marine Bio film Forming Bacteria (2016), dc voltage regulators, and Dc converters are utilised and also utilised in combination with an inductor to create a DC source (Fei 2016)( Kianpour 2016). Extraction and Purification of Antimicrobial Compounds from Marine Actinobacteria, A boost or buck converter (Chelvan 2016) are utilised, and it has various types of advantages such as constant current flow and easy structure. This is most important because of the resistances, and it affects serious degradation in the high step-up ratio and efficiency as the (Sethuramalingam 2016)A Proposed System of Ship Trajectory Control Using Particle Swarm Optimization is operating duty increases further, in high step up results in severe reverse recovery problem and it requires a snubber circuit to clear this issue (Pushpam 2016)( Nivetha 2015). To conquer this limitation, various types of step-up converters, utilising the voltage conversion capability of a transformer, can be adopted. Presented solutions to the above issues involve:

- A Forward converter, fly back converter is transformer-based converters reducea very low losses, and the switch provides to high voltage stress.

- Two energy-processing stages are implemented to prevent from the high-frequency connection of two boost converters and two sets of active switches, controllers and magnetic components that have to be coordinated.

- Hybrid converters with Transformer less are defined switched capacitor and switched inductor cell uses presenting a minimises and limits DC gain. 
These converters can able to gives higher voltage gain compare to than the traditional dc-dc boost converter. The high gain Voltage of these converters. If higher voltage gain is required, these converters can be capable of offering cascade considerable power stages, which will outcome in low efficiency.

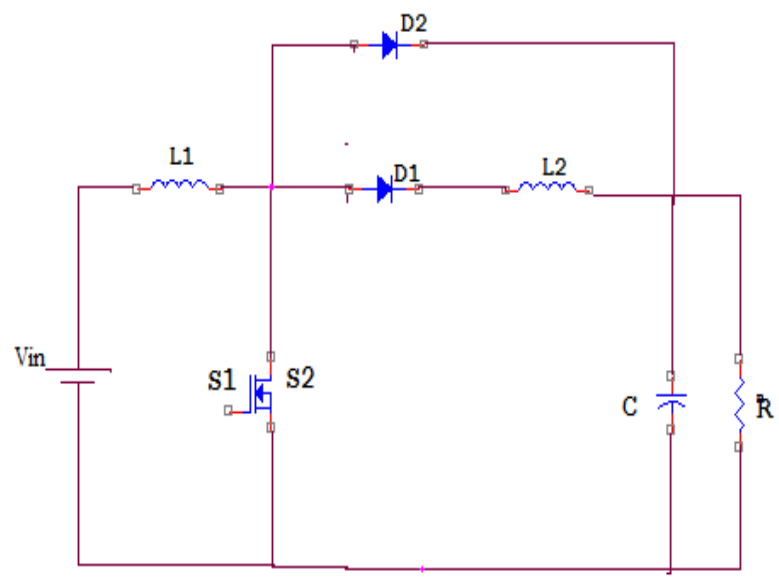

Figure 1: Conventional High Step Up-Dc Converter

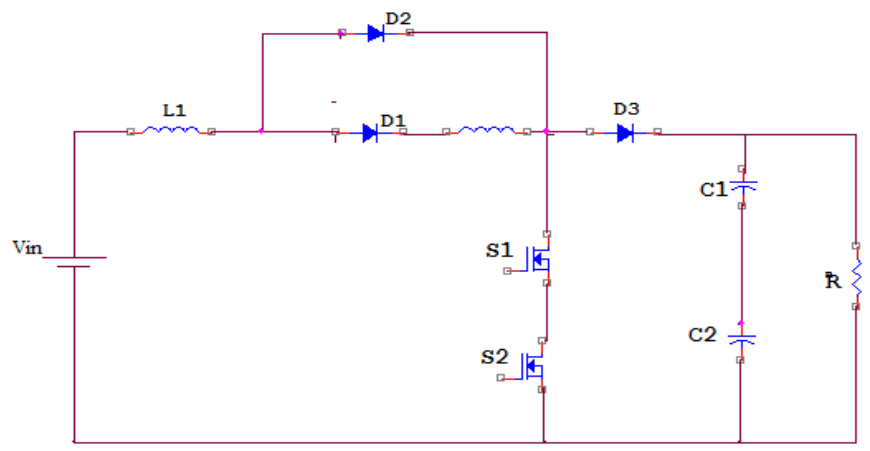

Figure 2: Proposed High Step-Up DC-DC Converter for Marine Applications

\section{MODES OF OPERATING OF THE PROPOSED CONVERTER}

\section{Mode 1:- [T0, T1]}

Turned on s1 and s2, at t=t0.dc energy flows to isLk1 and Lm through S1, and S2, D3, so the currents ILM, iLk1, and iD3 are increases. The energy stored in Lk2 is and Lk1 through S1, andS2, D4. Accordingly, iLk2 is decreased. In the meantime, the energy stored in $\mathrm{Lk} 2$ is used. The energies stored inC1 and $\mathrm{C} 2$ are discharged. At $\mathrm{t}=\mathrm{t} 1$

The energy stored in CS2 is fastly and completely discharged.

\section{Mode 2:- [T2, T3]}

The Dc energy flows to Lm, Lk1, and CS1. Continuously, In capacitor energy is stored and still discharged to the load.

\section{Mode 3:- [T4, T5]}

Turned off s1 and turned on S2. The DC source, Lm, Lk1, and Lk2 are series-connected to relocate their energies to Capacitor and the load. ThusiLk1, and iLk2, ILM, are reduced. The energy stored in C2 is still discharged to the load. 


\section{Mode 4:- [T6, T7]}

Turned-on s1 and s2. What the energy flows to Dc source is still transferred to Lk1 and Lm. Accordingly, increased inductor him. In the capacitor, the energy is stored and again discharged to the load.

\section{Mode 5:- [T8, T9]}

At $\mathrm{t}=\mathrm{t} 9$ the method ends when iLk1 is equal to iLk2. In this period Turned on $\mathrm{s} 1$ and turned off $\mathrm{s} 2$. The DC source flows, inductor Lk1 and Lm is series-connected to move their energies to capacitor C2, inductor Lk2 and the load. Accordingly, inductor values are reduced, and iLk2 has increased the energy stored in Lk1 is reused to C2 and the load. The energy stored in capacitor $\mathrm{C} 1$ is still discharged to the load.

\section{SIMULATION RESULTS}

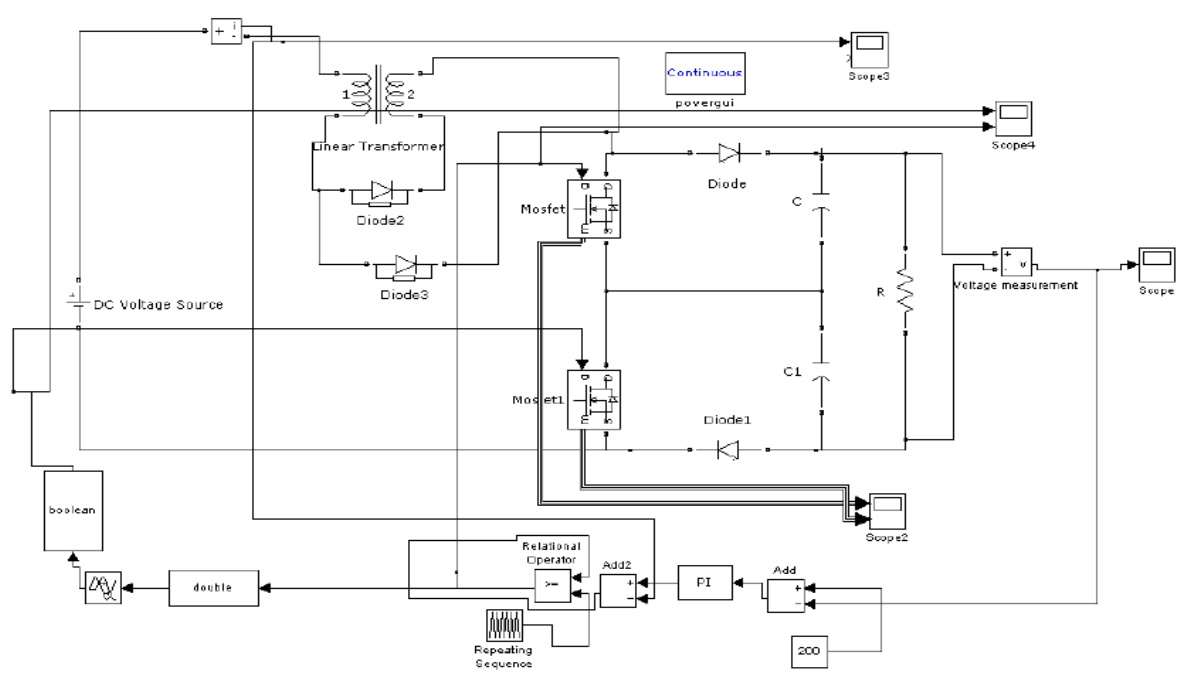

Figure 3: Simulation Circuit

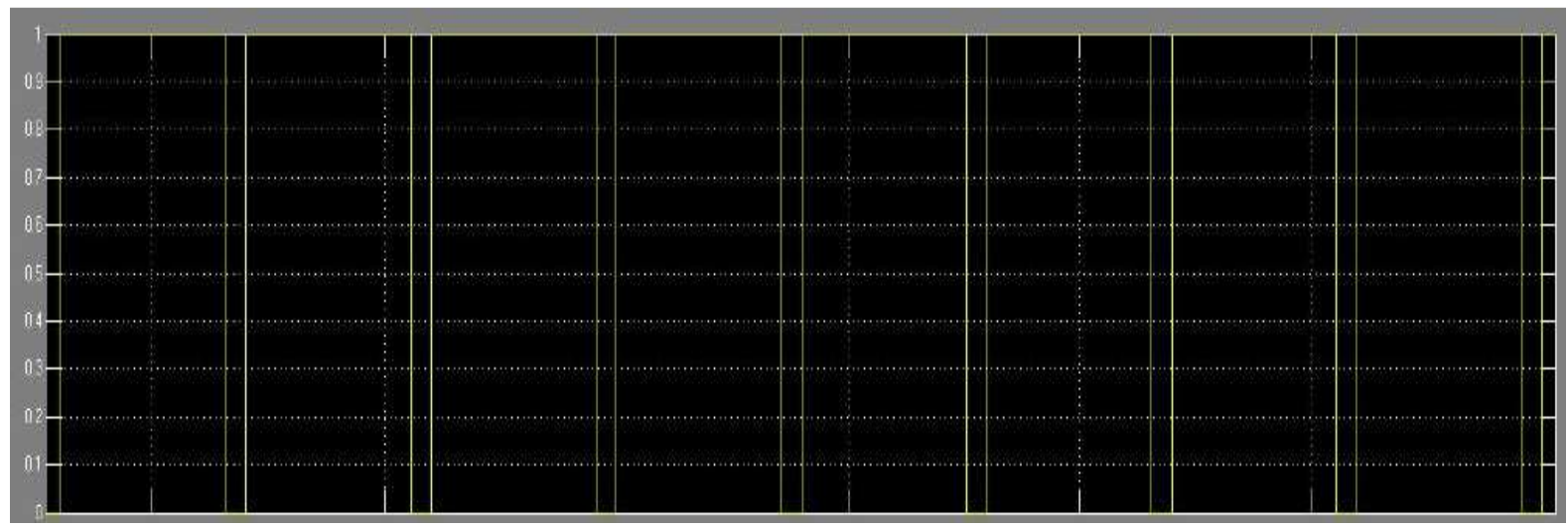

Figure 4: Gate Pulses 


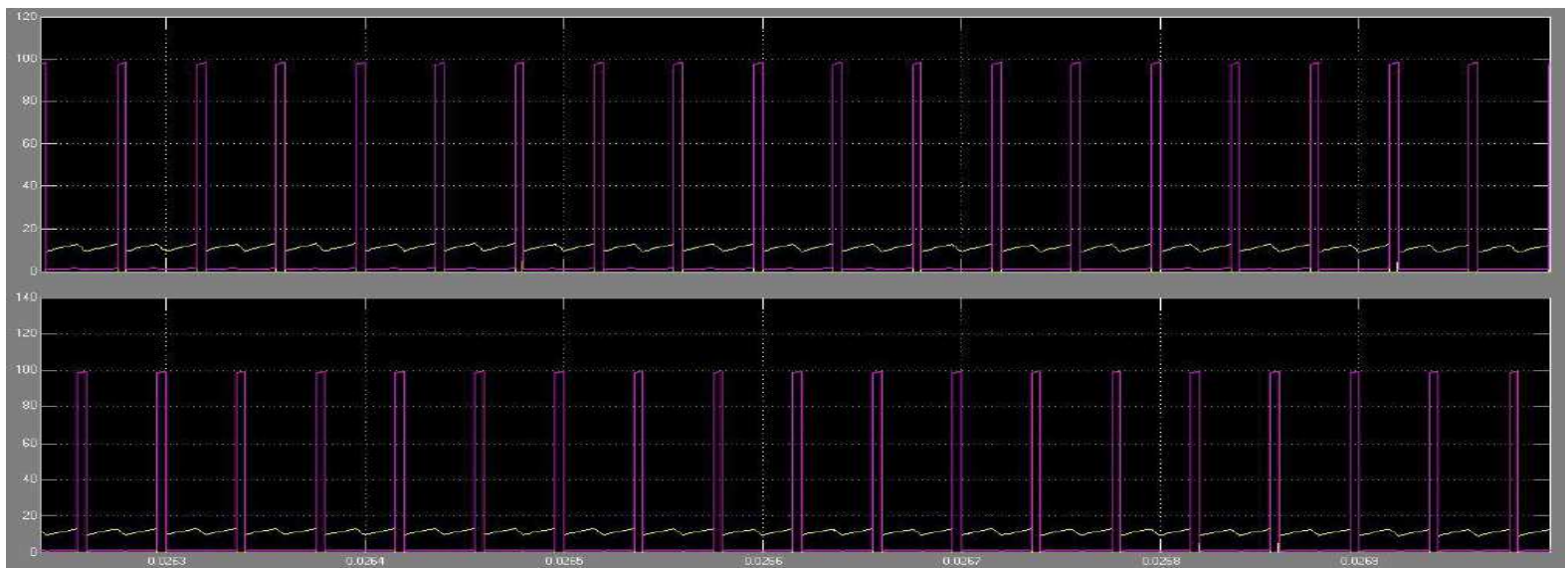

Figure 5: Voltage and Current Waveforms of Switch

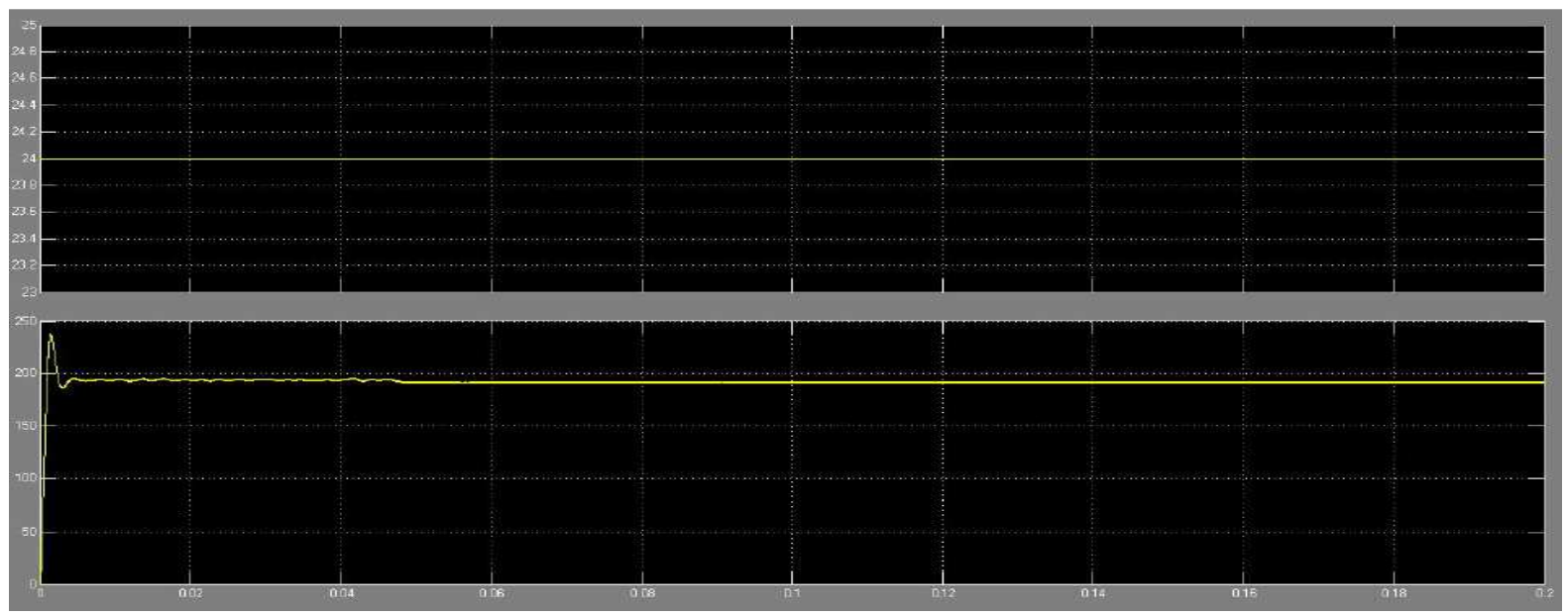

Figure 6: Output Voltage

\section{CONCLUSIONS}

The proposed circuit has the following several advantages compared to the conventional boost converters: A new high step-up boost converter using the voltage doubler was recommended. The developed method minimises the issue of high duty ratio or complexity of circuits in the traditional topology. It reduces the low voltage stress, higher boost rate, high efficiency, this converter can be used to various high boost applications, such as a marine application and military application etc.

\section{REFERENCES}

1. Zogogianni., et al., (2016) "Energy Savings in Marine Applications using thermoelectric modules and high step-up DC/DC converter".

2. Zarkadis, N.A., et al.,(2016) "Investigation of the behaviour of a high step-up DC/DC converter used in a Waste Heat Recovery System for marine applications" IEEE Conference on Power Electronics and Applications, 1-10.

3. E. Sathishkumar, Analysis and Design of High Step-Up Boost Converter Integrated with Sepic Converter, International Journal of Electronics, Communication \& Instrumentation Engineering Research and Development (IJECIERD), Volume 2, Issue 1, January - February 2012, pp. 36-46

4. Fei, L. \& Liu, H., (2016)"A novel cascaded Couple Inductor-Reverse high step-up converter integrating three-winding coupled 
inductor and diode-capacitor technique for renewable energy systems" IEEE Transactions on Industrial Informatics.

5. Kianpour, A., et al., (2016)“ High step-up floating output interleaved input coupled inductor-based boost converter" IEEE Iranian Conference on Electrical Engineering (ICEE), 1088-1093.

6. Chelvan, Y., et al., (2016) "Extraction and Purification of Antimicrobial Compounds from Marine Actinobacteria. Research Journal of Pharmacy and Technology”, Vol. 9, No. 4, 381-385.

7. Sethuramalingam, T.K. \& Nagaraj, B., (2016) “A Proposed System of Ship Trajectory Control Using Particle Swarm Optimization”, Procedia Computer Science, 87, 294-299.

8. A. Srilatha, Fatimaazra \& R. Venkateswarlu, Fuzzy Logic Controlled Bidirectional Dc-Dc Converter Applied to Dc Drive, International Journal of Electrical and Electronics Engineering Research (IJEEER), Volume 4, Issue 6, November - December 2014, pp. 25-36

9. Pushpam, A.C., et al., (2016) "Evaluation of the Antibiofilm Properties of Arthrobacter defluvii AMET1677 Strain Isolated from Shrimp Pond Sediment against Marine Biofilm Forming Bacteria”, Research Journal of Pharmacy and Technology, Vol. 9, No. 4, 373-380.

10. Nivetha, R., (2016)"Comparative Study and Design Analysis of Several Pulse Width Modulation Control Techniques." International Journal of MC square scientific research, vol. 7, No. 1, 57-65. 
